\title{
Regulation of Coremium Morphogenesis in Penicillium claviforme
}

\author{
By SARAH C. WATKINSON* \\ Department of Agricultural Science, University of Oxford, Oxford $O X_{\mathrm{I}}{ }_{3} R A$
}

(Received I8 September 1974)

SUMMARY

Coremia of Penicillium claviforme develop in three stages: primordium formation, elongation, and sporulation. Primordium formation was induced by external nutrients, while starvation initiated the differentiation of primordia into coremia with sporeheads. There is strong evidence that external nutrients are not taken up during this differentiation. Continued sporulation by mature coremia again required an external nutrient supply.

\section{INTRODUCTION}

Penicillium claviforme Bainier was first isolated from a pharmaceutical preparation of oak bark (Bainier, 1905). This fungus bears its spores on coremia, vertical stalks composed of aggregated hyphae. In a colony on nutrient agar, coremia develop in circles behind the colony margin, being initiated periodically. Although there is in many isolates an endogenous rhythm of coremium initiation of the order of 24 to $48 \mathrm{~h}$, this may be either overridden or reinforced by cyclic changes in temperature or illumination, or accentuated by the presence of certain chemicals in the medium (Faraj-Salman, I970, I97 I $a, b$ ). Carlile, Lewis, Mordue \& Northover (I96I) gave an account of coremium morphogenesis showing that light was necessary and that the nature of the medium affected the numbers of initials and mature coremia formed in a colony. Initials over $2 \mathrm{~mm}$ in height could be excised and would still complete their development to form sporeheads. Such endotrophic development of fruit body primordia has been described in other fungi, for example Coprinus cinereus (Gooday, 1974) and Isaria cretacea (Taber, I960), and must necessitate a preliminary accumulation of endogenous substrates.

It was hoped that a study of nutritional control of morphogenesis, including the alternation of accumulation and utilization of reserves that must accompany coremium formation, might throw light on the mechanisms that regulate differentiation. Penicillium claviforme coremia have the advantages that there is synchrony between their component hyphae, at least during the three main morphogenetic phases of initiation, elongation, and sporulation, and the production of the coremia can easily be controlled. These three stages were examined in terms of the effect of the presence and absence of an external nutrient supply. No attempt was made to examine the effects of separate components of the medium because the omission of components was found to lead to abnormalities in a development that is in any case complex. As far as possible single coremia or young colonies were used to minimize the morphogenetic effects of volatile substances produced by the fungus (Piskorz, 1970). The

\footnotetext{
* Present address: Department of Botany, University of Oxford.
} 
term 'primordium' is used in this paper to mean a young coremium with a recognizable apical growing point but without a sporehead.

\section{METHODS}

The isolate IMI 44744 of $P$. claviforme used throughout was obtained from the Commonwealth Mycological Institute, Kew, and maintained on $3 \%$ malt agar plates. All media used in experiments were based on the Czapek-Dox formula ( $\mathrm{g} / 1$ distilled water): $\mathrm{NaNO}_{3}, \mathbf{2}$; $\mathrm{KH}_{2} \mathrm{PO}_{4}, \mathrm{I} ; \mathrm{MgSO}_{4} .7 \mathrm{H}_{2} \mathrm{O}, 0.5 ; \mathrm{KCl}, 0.5 ; \mathrm{FeSO}_{4} .7 \mathrm{H}_{2} \mathrm{O}$, 0.0I; sucrose, 30; Oxoid No. 3 agar, 20. Where stated, Oxoid acid casein hydrolysate was substituted for $\mathrm{NaNO}_{3}$ and the concentrations of both this and sucrose were varied. Media were sterilized by autoclaving at $\mathrm{I} 2 \mathrm{I}{ }^{\circ} \mathrm{C}$ for $\mathrm{I} 5 \mathrm{~min}$. Plastic Petri dishes $9 \mathrm{~cm}$ in diameter were used, with $20 \mathrm{ml}$ medium/ plate. When it was desired to separate mycelium from agar during an experiment, colonies were grown on circles of sterile cellophane placed on the agar before inoculation. All cultures were kept at $25 \pm 2{ }^{\circ} \mathrm{C}$ unless otherwise stated, and were continuously illuminated by $8 \mathrm{~W}$ fluorescent strip lights $\mathrm{I} 5$ to $30 \mathrm{~cm}$ above the plates.

Estimations of glycogen in mycelium were made by first boiling samples in two changes of $80 \%(\mathrm{v} / \mathrm{v})$ ethanol to remove soluble sugars, washing, and then degrading the glycogen by incubating the residue with amyloglucosidase at $50{ }^{\circ} \mathrm{C}$ in citrate-phosphate buffer at $\mathrm{pH}$ 4.4 for $2 \mathrm{~h}$. The filtrate was assayed for glucose by the glucose oxidase method (Sigma Technical Bulletin No. 510). The mycelial residue was washed and dried to constant weight at $80^{\circ} \mathrm{C}$. Glycogen estimations are given as percentages of this residual mycelial dry weight.

Measurements of coremium heights were made either with dividers and a steel rule or with a vertical travelling microscope. Numbers of spores per coremium were counted in a haemocytometer. The suspension for counting was made by first crushing the sporeheads gently in portions of $0.01 \%$ 'Savona' laboratory detergent (Première Polish Co.) and then sonicating for $5 \mathrm{~s}$, using a Dawes sonic probe at approximately $6 \%$ maximum output, to break the spore chains into single spores.

\section{RESULTS}

\section{Induction of coremium development by starvation}

Six $100 \mathrm{ml}$ conical flasks, each containing $25 \mathrm{ml}$ of a liquid medium with (per litre) $10 \mathrm{~g}$ casein hydrolysate, $50 \mathrm{~g}$ sucrose and minerals, were inoculated with approximately $4 \times 10^{6}$ spores/flask. After I 4 days a thick vegetative mycelium had developed in all the flasks. The medium in three of them was then removed and replaced by a medium containing minerals only. Six days later, over 200 sporulating coremia had appeared in each of these flasks and none in the three control flasks in which the original medium remained.

Samples from similar cultures were harvested daily for 6 days after the removal of the nutrient medium and their glycogen content estimated. This fell from $0.9 \%$ to $0.3 \%$ of residual mycelial dry weight. The formation of mature (i.e. grey-green) spores at 4 days after removal of the medium occurred at a net glycogen content of $0.5 \%$.

\section{Induction of primordium formation}

In the above experiment starvation induced the elongation and sporulation of coremium primordia in the colony. However, as this process is endotrophic the formation of the primordia themselves probably requires the presence of sufficient exogenous nutrients for their accumulation to occur within the hyphae. To test whether high nutrient concentrations in the medium, which presumably induce such accumulation, would also induce primordium 
Table I. Induction of primordia in discs of undifferentiated mycelium on transfer to medium of various concentrations

Concn of medium*

No. of primordia/disc at $48 \mathrm{~h} \dagger$

$\begin{array}{ccccc}I & \frac{1}{2} & \frac{1}{4} & \frac{1}{8} & \frac{-1}{16} \\ 24 \cdot 3 \pm 2 \cdot 8 & 19 \cdot 3 \pm I \cdot 0 & 14 \pm 3 & 8 \cdot 3 \pm I \cdot 5 & 2 \cdot 3 \pm I \cdot 3\end{array}$

* The undiluted medium contained $\left(\mathrm{g} / \mathrm{l}\right.$ distilled water): sucrose, 50 ; acid casein hydrolysate, $10 ; \mathrm{KH}_{2} \mathrm{PO}_{4}$, I; $\mathrm{KCl}, 0.5 ; \mathrm{MgSO}_{4} .7 \mathrm{H}_{2} \mathrm{O}, 0.5 ; \mathrm{FeSO}_{4} .7 \mathrm{H}_{2} \mathrm{O}, 0.01$. All media contained $2 \%$ agar.

$\dagger$ Means of five experiments, and standard deviations.

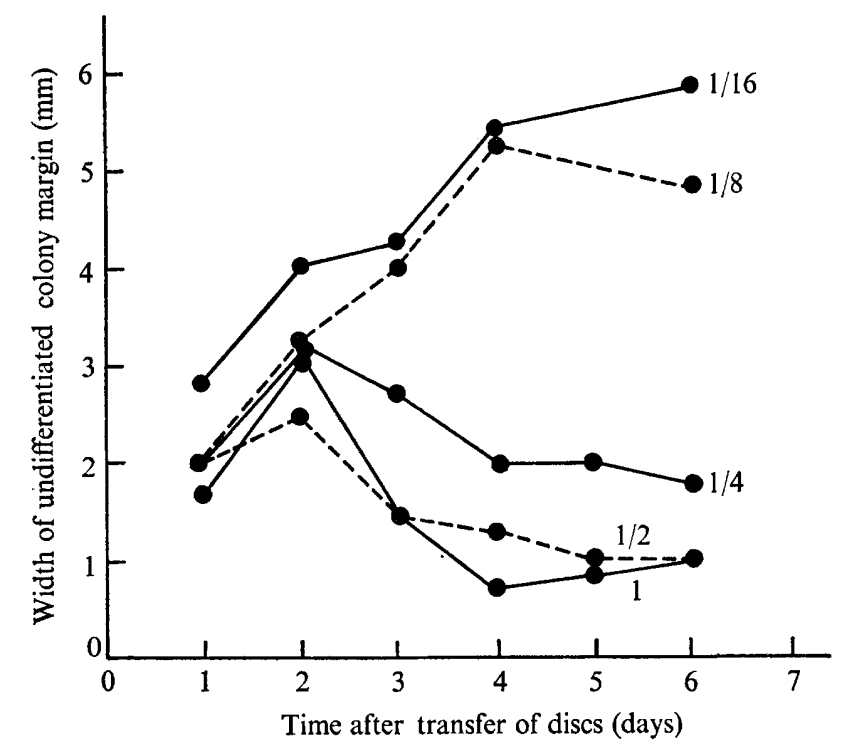

Fig. I. Distances behind the colony margin at which primordia developed on agar medium with nutrients at $I$ to $\frac{1}{16}$ dilutions. Each point represents averages from three plates. Mean radial growth rate was 0.9 to $1 \cdot \mathrm{I} \mathrm{mm} /$ day at all concentrations.

formation in undifferentiated mycelium, discs of mycelium $4 \mathrm{~mm}$ in diameter and containing no visible primordia were cut with a cork borer from young, non-sporing colonies grown on cellophane over agar medium with nutrients at $\frac{1}{4}$ standard concentration. On this medium coremium formation is limited but there is good growth of undifferentiated mycelium. The discs were detached from the cellophane and laid on fresh agar medium at a series of nutrient concentrations. Five plates were used at each concentration and only one disc was placed in the middle of each plate. Forty-eight hours after this transfer primordia had formed in the discs, the numbers varying with nutrient concentration, the more dilute media producing fewer primordia (Table I). There was little or no new marginal growth at this stage.

The quantitative relationship between nutrient concentration and primordium numbers suggests that nutrient availability can determine whether differentiation of primordia occurs, i.e. it triggers this stage of coremium morphogenesis. Since the $48 \mathrm{~h}$ primordia were large enough to be seen clearly with the naked eye, the morphogenetic effect on the hyphae of an exogenous nutrient supply must have begun earlier. Other observations showed that primordia can develop from hyphae in under $20 \mathrm{~h}$ at $25^{\circ} \mathrm{C}$. 


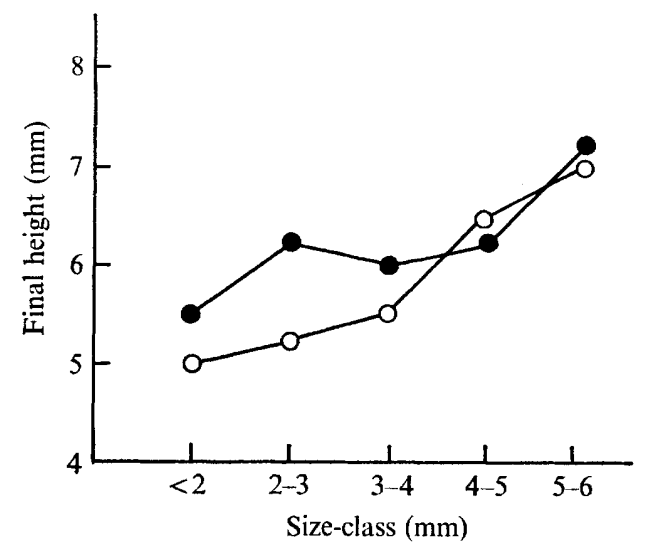

Fig. 2

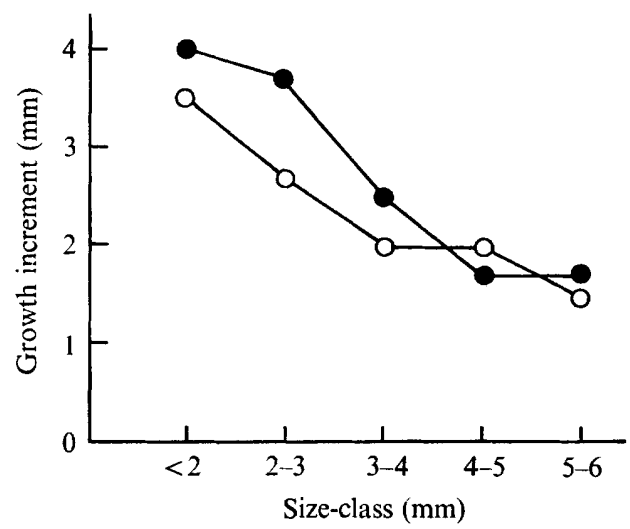

Fig. 3

Fig. 2. Relationship between final height of coremium and initial height of primordium. Each point represents the mean of 6 individuals in each size-class. Primordia on Czapek-Dox agar; $O$, primordia on water agar. Only significant components of the interaction sums of squares are shown:

$$
\begin{aligned}
\text { lin } \times \text { cub } & =1 \cdot 63, \\
\text { Total } & =2.82 .
\end{aligned}
$$

Fig. 3. Relationship between growth increment (final height minus initial height) and initial height. Symbols and results of analysis as in Fig. 2. Interaction sum of squares:

$$
\begin{aligned}
\text { lin } \times \text { cub } & =1 \cdot 63, \\
\text { Total } & =2.90 .
\end{aligned}
$$

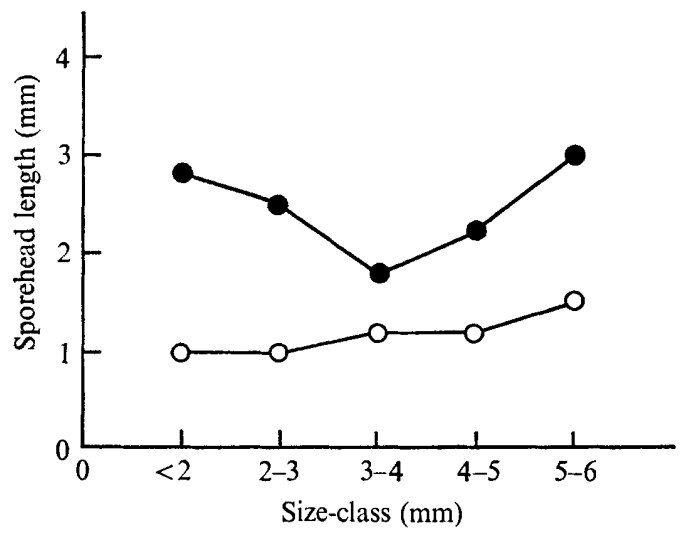

Fig. 4. Relationship between sporehead size and initial height. Symbols and results of analysis as in Fig. 2. Interaction sums of squares:

$$
\begin{aligned}
\operatorname{lin} \times \operatorname{lin} & =0.602, \\
\operatorname{lin} \times \text { quad } & =1.823, \\
\text { Total } & =2.958 .
\end{aligned}
$$

Frequency of primordium initiation during growth on media of various concentrations

Following the above observations, colonies were allowed to develop from the discs of mycelium. Their mean radial growth rates, and the mean distance behind the advancing margin of the outermost new primordia, were recorded (Fig. I). Measurements were made along 2 diameters of each colony, at right angles, chosen each day so as to include the primordia nearest the margin.

The frequency of primordium formation was much reduced at low concentrations even 
though the radial growth rate was almost unaffected. Nutrient availability would appear to have over-ridden any endogenous periodicity in coremium development.

\section{Elongation and sporulation of excised coremia}

Gooday (1974) demonstrated the endotrophic nature of stipe elongation in Coprinus cinereus by measurements of excised stipes elongating with and without an exogenous nutrient supply, and by the use of metabolic inhibitors. The same method was adopted here for investigating nutrient requirements for coremium elongation. This elongation is apical, rather than intercalary as in $C$. cinereus, but resembles that of Coprinus stipes in being endotrophic.

A $4 \%$ malt agar medium was used for the production of large numbers of primordia of differing sizes. Agar plates were covered with cellophane and inoculated along a diameter with a spore suspension. After I I days, mycelium had developed in the form of a strip about $2 \mathrm{~cm}$ wide across each plate with a good range of developing primordia near the outside edges. These were excised by cutting out a small square (about $\mathrm{I} \mathrm{mm}^{2}$ ) of mycelium round the base of each. This formed a 'foot' so that the primordia could be stood on an agar surface. The excised primordia were measured and divided by size into five classes: $<2 \mathrm{~mm}, 2$ to $3 \mathrm{~mm}, 3$ to $4 \mathrm{~mm}, 4$ to $5 \mathrm{~mm}$, and 5 to $6 \mathrm{~mm}$. Any adherent cellophane was removed and the primordia were stood on either nutrient agar (Oxoid Czapek Dox) or water agar. At least ten individuals were used in each size-class, each one being identified by a number on the base of the plate. The primordia were allowed to complete their development and the height of each resulting coremium was measured at 6 days after transfer. At 8 days the measurements were repeated to ensure that elongation had finished, and the lengths of the sporeheads were recorded as well. The height of the coremium was measured from the foot to the top of the sporehead. This gave the best approximation to the true length of the coremium, paraffin sections of the sporehead having shown that this forms as a cap around the apex rather than as a ball on top of it.

For statistical analysis of the data, samples of 6 individuals were selected at random from each size-class. An analysis of variance was carried out on these data in relation to the main effects of exogenous nutrient, supply and initial height on final size elongation, and sporehead size. The interactions of these effects were found to be significant and therefore the interaction sums of squares were partitioned into their linear components (Figs. 2 to 4 ).

\section{Effect of initial size and nutrient supply}

Effect on final size. The analysis revealed a highly significant tendency for final size to show a positive trend with initial size. Supplying nutrients slightly increased the final size attained by the smallest primordia, and this interaction between the variables of initial size and nutrient supply was just significant. The implication of this for coremium development would seem to be that the amount of endogenous nutrient resources depends on the size of the primordium and that the contribution of exogenous nutrients probably becomes less as differentiation proceeds.

Effect on growth increment. There was a highly significant inverse relationship between initial size and subsequent growth. Small primordia all elongated more than large ones even if they never overtook them. This suggests that coremia tend to attain a given height irrespective of their total nutrient resources. There may be a mechanism for switching from elongation to sporulation which operates sooner in the larger excised primordia, allowing available endogenous substrates to be shared between the two successive processes.

Again, exogenous nutrients promoted elongation only when supplied to the smallest primordia, suggesting an increasing nutritional independence as the coremium develops. 
Table 2. The effect of various inhibitors on elongation of coremium and mycelial growth

\begin{tabular}{|c|c|c|c|}
\hline Inhibitor & $\begin{array}{l}\text { Inhibitor } \\
\text { concn } \\
(\mathrm{mg} / \mathrm{ml})\end{array}$ & $\begin{array}{l}\text { Coremium } \\
\text { elongation }\end{array}$ & $\begin{array}{l}\text { Radial growth } \\
\text { rate of colonies } \\
\text { ( } \% \text { control) }\end{array}$ \\
\hline Potassium cyanide & 0.05 & 0 & o \\
\hline Nystatin & 0.003 & o & 0 \\
\hline 2,4-Dinitrophenol & $\begin{array}{l}0.4 \\
0.04\end{array}$ & $\begin{array}{l}\leqslant \mathrm{I} \mathrm{mm} \\
\leqslant \mathrm{I} \mathrm{mm}\end{array}$ & $\begin{array}{l}50 \\
88\end{array}$ \\
\hline 2-Deoxy-D-glucose* & $\begin{array}{r}10 \\
100\end{array}$ & $\begin{array}{l}\leqslant \mathrm{I} \mathrm{mm} \\
\leqslant \mathrm{I} \mathrm{mm}\end{array}$ & $\begin{array}{l}25 \\
\text { NT }\end{array}$ \\
\hline Glucosamine & $\begin{array}{r}10 \\
100\end{array}$ & $\begin{array}{l}\leqslant \mathrm{I} \mathrm{mm} \\
\leqslant \mathrm{I} \mathrm{mm}\end{array}$ & $\begin{array}{l}50 \\
\text { NT }\end{array}$ \\
\hline Griseofulvin & 0.003 & $\leqslant \mathrm{I} \mathrm{mm}$ & NT \\
\hline D-Gluconic acid* & $\begin{array}{l}50 \\
10\end{array}$ & $\begin{array}{l}\text { Sometimes < }<\mathrm{mm} \dagger \\
\text { Sometimes }<\mathrm{I} \mathrm{mm} \dagger\end{array}$ & $\begin{array}{c}(30 \% \text { at } 100 \mathrm{mg} / \mathrm{ml}) \\
\text { NT }\end{array}$ \\
\hline 5-Fluorouracil & 5 & Sometimes < $\mathrm{I} \mathrm{mm} \dagger$ & 0 \\
\hline Sodium azide & 0.05 & $\begin{array}{l}\text { Sometimes < } 1 \mathrm{~mm} \dagger \\
\text { Sometimes < } 1 \mathrm{~mm}\end{array}$ & 0 \\
\hline
\end{tabular}

Effect on sporehead size. In the absence of external nutrients, there was a small but significant positive linear trend of sporehead size with initial size. However, there was a highly significant difference between this linear relationship and the curve of sporehead size in the presence of nutrients. Here all the sporeheads were bigger than those in the water treatment, but the greatest effect was on the smallest and largest primordia.

A possible interpretation is that small primordia are capable of taking up and storing nutrients, but that they lose this capacity as they begin to differentiate sporeheads at $3 \mathrm{~mm}$ height. When differentiation is complete and sporulation is established, exogenous nutrients can again be taken up, translocated up the coremium stalk, and used in spore formation. Primordia that were of middle size at the time of transfer would, on this interpretation, have been differentiating exclusively endotrophically and would therefore have lagged behind the others in the utilization of exogenous nutrients.

\section{Effect of metabolic inhibitors on elongation}

To compare the pattern of inhibition of coremium elongation with that of Coprinus stipe elongation demonstrated by Gooday (1974), excised primordia, approximately $2 \mathrm{~mm}$ in height, were placed inside separate specimen tubes $(\mathrm{I} 2 \times 50 \mathrm{~mm})$ on wads of filter paper previously saturated with the inhibitor solution to be tested, and the tubes were plugged. Four coremia were used in each test and controls were run with distilled water substituted for inhibitor solution. Primordia were measured on transfer to the tubes and again $48 \mathrm{~h}$ later, using a travelling microscope. Separate measurements were made of the radial growth rates of colonies on nutrient agar incorporating each inhibitor. One $\mathrm{ml}$ of inhibitor solution was dispensed into a $9 \mathrm{~cm}$ Petri dish and $15 \mathrm{ml}$ of cool modified Czapek-Dox agar (containing $30 \mathrm{~g}$ sucrose and $3.2 \mathrm{~g}$ casein hydrolysate/l) were mixed with it. Plates were inoculated centrally with a disc of non-sporing mycelium. Colony diameters were recorded on five successive days by taking the mean of measurements of the same two diameters at right angles 
each time and starting at 5 days after inoculation, with 3 replicates for each inhibitor. Radial growth rates did not change during the 5 days.

Controls for the whole series of experiments gave coremium elongations of $\mathrm{I} \cdot 7 \pm 0.5 \mathrm{~mm}$ and a mean colony radial growth rate of $2 \mathrm{~mm} /$ day. With two of the inhibitors there was no elongation at all. Several inhibitors reduced elongation to I $\mathrm{mm}$ or less for all four coremia used, and some did this with only two or three coremia (Table 2). Some inhibitors had no effect on elongation, including $(\mathrm{mg} / \mathrm{ml})$ : sodium undecylenate, 2; penicillin, I; chloramphenicol, I; colchicine, I; cycloheximide, $0 . \mathrm{I} ; 8$ azaguanine, 0.05; sodium fluoride, 0.05 . The ineffectiveness of cycloheximide as an inhibitor of elongation was particularly striking because colony radial growth was totally inhibited at $0 \cdot \mathrm{I} \mathrm{mg} / \mathrm{ml}$. However, no experiments were done on the uptake of inhibitors that did not affect elongation.

Coremium elongation resembled Coprinus stipe elongation in being inhibited by respiratory inhibitors, glucose analogues and 5-fluorouracil. It differed in being unaffected by cycloheximide at twenty times the concentration used by Gooday (1974), and in being sensitive to nystatin and griseofulvin. These differences possibly resulted from physical differences in development. The hyphae of the coremium grow apically and the processes of tip growth may well be similar to those in undifferentiated mycelium. To prevent growth of the coremium hyphal tips, an inhibitor must either be translocated there, or interfere with the processes of translocation or metabolism themselves. Griseofulvin is probably translocated to the apex. Cycloheximide may be ineffective because it is not translocated to the major sites of protein synthesis. The other effective inhibitors may act by interfering with metabolic and transport processes without necessarily reaching the coremium apex at all.

\section{Contribution of exogenous nutrients to sporulation}

The relationship between initial height of excised coremia and sporehead size (Fig. 4) suggested that nutrients supplied to the base of differentiated coremia could be taken up and used in spore formation. This hypothesis was tested as follows. Large numbers of primordia of the same size were produced by inoculating the entire cellophane-covered surface of an agar plate with a spore suspension. The medium chosen for this was known to support good mycelial growth with fairly numerous but well separated coremia, and contained (per litre) $12.5 \mathrm{~g}$ sucrose, $2.5 \mathrm{~g}$ casein hydrolysate, and minerals as in the Czapek-Dox formula. Approximately $2.5 \times 10^{6}$ spores in $0.5 \mathrm{ml}$ water were spread over the cellophane covering this medium in each plate. After incubation at $20^{\circ} \mathrm{C}$ for I week the plates contained numerous synchronously-developing, 3 to $4 \mathrm{~mm}$ high coremia, which had begun to develop spore heads although the absence of pigmentation showed that there were no mature spores.

These primordia were excised on a 'foot' of mycelium as before and stood on fresh agar medium, either water agar or $4 \%$ malt agar, in crystallizing dishes. One hundred ml medium per dish was used to give a depth of $15 \mathrm{~mm}$. Samples of four coremia from each treatment were harvested at I, 2, 3, 4 and 5 days after transfer. Sporeheads were removed with iridectomy scissors and suspended in pairs in $2 \mathrm{ml}$ of a $0.01 \%$ solution of 'Savona' laboratory detergent. An even suspension of spores was produced as described above and counted in a haemocytometer. Spore production was far greater on malt agar than on water agar (Fig. 5). This confirmed the expectation that on completion of differentiation, coremia regain their capacity for taking up and utilizing exogenous nutrients. 


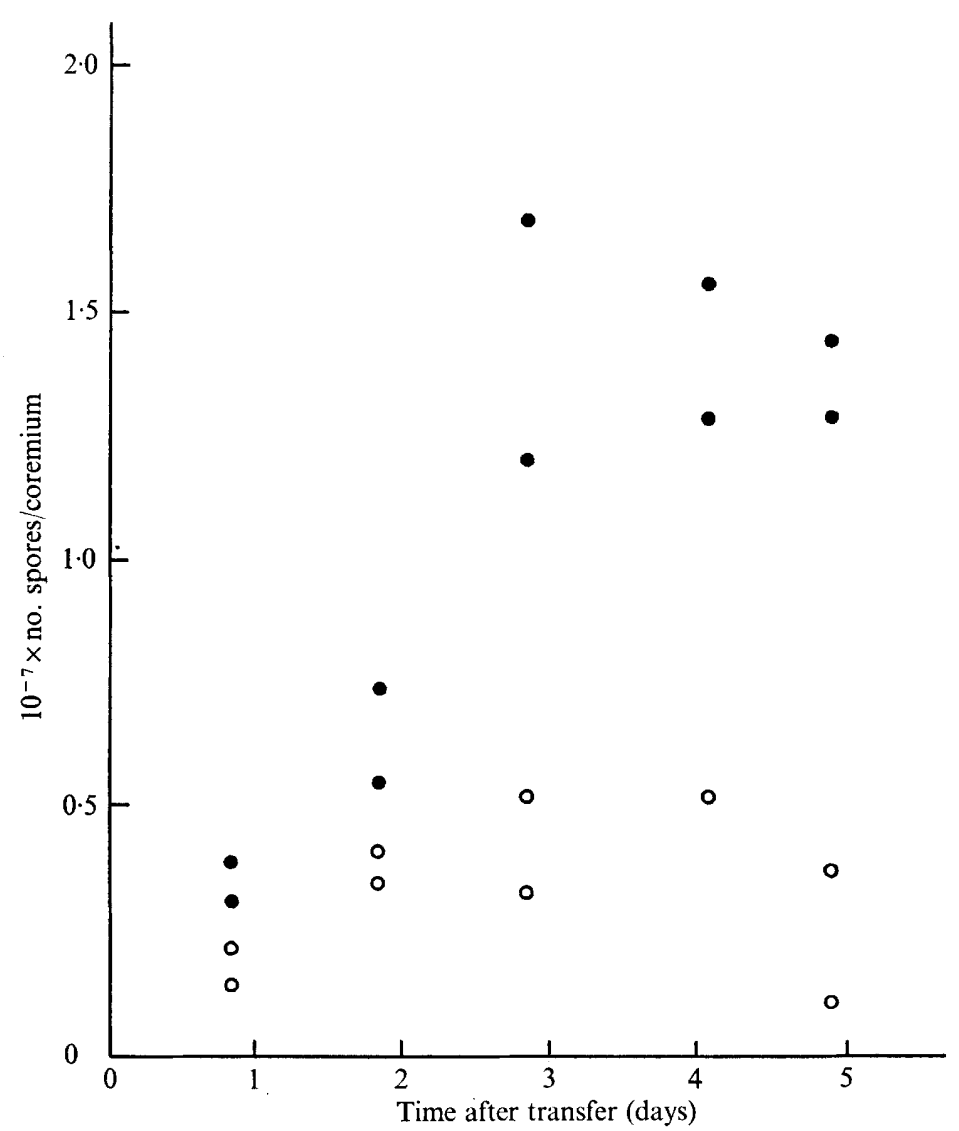

Fig. 5. Spore production by differentiated coremia. $\bigcirc$, Water agar; $0,4 \%$ malt agar. Each point represents a sample consisting of two sporeheads.

\section{DISCUSSION}

There was a period in coremium differentiation when exogenous nutrients were not required and were not utilized even if present. This was during the period in which the primordium with its organized multi-hyphal apex first elongated and then started to sporulate, the hyphal tips differentiating into conidiophores, losing their photosensitivity (Carlile et al. 196I) and budding-off chains of spores. The fact that the coremium during this active period of differentiation was in some way restricted to using only endogenous substrates supports Wright's (1973) view that nutritional isolation is often a prerequisite for differentiation.

The hypothesis that the cyclic initiation, elongation and sporulation of coremia seen in the colony could be controlled by changes in availability of exogenous nutrients was supported by the finding that two stages of coremium development can be induced in this way: high external nutrient concentration induced initiation of coremium primordia, and starvation induced the differentiation of pre-formed primordia. In a colony on nutrient agar a possible sequence of events might be: (i) mycelium accumulates sugars from the medium; (ii) sugars are polymerized and retained in the hyphae; (iii) nutrient levels in the medium fall because uptake by hyphae is faster than diffusion of solutes from unexploited parts of 
the medium; (iv) local starvation induces elongation; and (v) sporulation continues if external nutrients are replaced, e.g. by diffusion within the agar medium. The radial nature of colony growth means that there are circular zones where each phase of the cycle can be seen. Although this scheme is based on results from fungi in agar media, there is no reason why it should not operate in nature.

Two stages in coremium differentiation appeared to involve definite switches in morphogenesis. One was the nutrient-induced initiation of primordia, which merits further investigation in view of Jennings's (1974) suggestion that differentiation could be regulated by solute-transport mechanisms. The other was the change from normal hyphal-tip growth to conidiophore production, perhaps mediated by changing levels of endogenous substrates.

The author gratefully acknowledges a Junior Research Fellowship from St Hilda's College, Oxford. Dr H. C. Dawkins, Department of Forestry, University of Oxford, kindly carried out the statistical analysis of data presented in Figs. 2 to 4 .

\section{REFERENCES}

Bainier, G. (I905). Sur deux Penicillia. Bulletin trimestriel de la Société mycologique de France $2 \mathbf{I}$, I 27.

Carlile, M. J., Lewis, B. G., Mordue, E. M. \& Northover, J. (I96I). The development of coremia. I. Penicillium claviforme. Transactions of the British Mycological Society 44, 129-133.

Faraj Salman, A.-G. (1970). Einfluss von Licht auf die Koremienbildung und ihre kreisförmige Anordnung. Kulturpflanze $\mathbf{1 8 , 8 9 - 9 7 .}$

Faraj Salman, A.-G. (197I $a$ ). Zur Induktion einer endogenen Rhythmik bei Mutanten des Pilzes Penicillium claviforme Bainier. I. Wirkungsweise von Alkoholen. Archiv fïr Protistenkunde Ir3, 306-313.

Faraj Salman, A.-G. (197 I b). Zur Induktion einer endogenen Rhythmik bei Mutanten des Pilzes Penicillium claviforme Bainier. II. Wirkungsweise von Detergenten. Biochemie und Physiologie der Pflanzen r62, $470-473$.

Gooday, G. W. (1974). Control of the development of excised fruit bodies and stipes of Coprinus cinereus. Transactions of the British Mycological Society 62, 39I-399.

JENNINGS, D. H. (1974). Sugar transport into fungi: an essay. Transactions of the British Mycological Society 62, I-24.

PISKorz, B. (1970). Comparative investigations on the development of species from the Penicillium clavigerum section. II. Action of aeration on the morphology of the mycelium and coremia. Acta Societatis botanicorum Poloniae 39, 7I I-73I.

TABER, W. A. (1960). Studies on Isaria cretacea: morphogenesis of the synnema and endogenous nutrition. Canadian Journal of Microbiology 6, 53-63.

Wright, B. E. (1973). Critical Variables in Differentiation. Prentice-Hall. 